\section{Present-day temperature standard deviation parameterization for Greenland}

Modelling the surface mass balance of the Greenland ice sheet (GrIS) in large-scale ice-sheet models using temperature parameterizations in relation with the positive degreeday (PDD) approach is highly sensitive to a parameter: the temperature standard deviation (Braithwaite, 1984; Reeh, 1991). The PDD method is a statistical approach that relates the totals of positive near-surface air temperatures to the amount of snow or ice that melts. The standard deviation of the near-surface air temperature, $\sigma_{\text {pdd }}$, is important for PDD modelling because it indicates whether the temperature has been above freezing during a month even though the mean monthly near-surface air temperature value is below. Fausto and others (2009a) demonstrated that a uniform increase of $\sigma_{\text {pdd }}$ from $2.5^{\circ} \mathrm{C}$ to $4.5^{\circ} \mathrm{C}$ results in a $33 \%$ increase in the modelled melt area over Greenland where melt is $>1 \mathrm{~mm}$. It is therefore important to constrain the $\sigma_{\text {pdd }}$ value with observations. In large-scale ice-sheet and surface massbalance models of Greenland, it is common that $\sigma_{\text {pdd }}$ is assigned a single value which typically spans the interval 4.5-5.5 ${ }^{\circ} \mathrm{C}$ (Greve, 2005; Goelzer and others, 2010; Greve and others, 2011; Sundal and others, 2011). The value of $\sigma_{\text {pdd }}$ is often used as a tuning parameter, instead of using the temperature standard deviations observed at the automatic weather stations (AWSs) on the ice sheet. To add to the temperature parameterization presented by Fausto and others (2009a), it is proposed to construct a similar distributed parameterization for the temperature standard deviation using the same dataset.

Commonly, large-scale ice-sheet models over Greenland calculate the amount of melt using the PDD method by assuming an annual sinusoidal evolution of the near-surface air temperature (Reeh, 1991). The number of PDDs from the normal probability distribution around the monthly mean temperatures during the years, following Reeh (1991), is given as

$$
\mathrm{PDD}=\int_{0}^{A} \frac{1}{\sigma_{\mathrm{pdd}}(t) \sqrt{2 \pi}} \int_{0}^{\infty} T \exp \left(\frac{\left(T-T_{\mathrm{anc}}(t)\right)^{2}}{2 \sigma_{\mathrm{pdd}}^{2}(t)}\right) \mathrm{d} T \mathrm{~d} t,
$$

where $t$ is the time, $T\left({ }^{\circ} \mathrm{C}\right)$ is the near-surface air temperature $(2 \mathrm{~m}), T_{\text {anc }}\left({ }^{\circ} \mathrm{C}\right)$ is the annual near-surface temperature cycle and $\sigma_{\text {pdd }}$ is the standard deviation of the near-surface air temperature. $T_{\text {anc }}$ is assumed to vary sinusoidally over time,

$$
T_{\text {anc }}(t)=T_{\mathrm{a}}+\left(T_{\mathrm{j}}-T_{\mathrm{a}}\right) \cos \frac{2 \pi t}{A},
$$

where $A$ is 1 year. $T_{\mathrm{j}}$ and $T_{\mathrm{a}}$ are the mean July and mean annual near-surface air temperatures. $\sigma_{\text {pdd }}$ is also assumed to vary sinusoidally over time,

$$
\sigma_{\text {pdd }}(t)=\sigma_{\mathrm{a}}+\left(\sigma_{\mathrm{j}}-\sigma_{\mathrm{a}}\right) \cos \frac{2 \pi t}{A},
$$

where $\sigma_{\mathrm{j}}$ and $\sigma_{\mathrm{a}}$ are the mean July and mean annual standard deviation of the near-surface air temperatures.

Based on Reeh (1991) and following the study of Fausto and others (2009a), the annual mean $\left(T_{\mathrm{a}}\right)$ and July mean $\left(T_{\mathrm{j}}\right)$ near-surface air temperatures are parameterized as a linear function of altitude, latitude and longitude.

The standard deviation of the near-surface air temperature over the GrlS is parameterized using data from AWSs located on the ice sheet. The parameterization is expressed in terms of mean annual and mean July temperature standard deviations. Mean monthly values are calculated from hourly temperature observations for each month in a given year for the Greenland AWSs (for details see fig. 2 and tables 2 and 3 in Fausto and others, 2009a). The associated standard deviations around the monthly means were calculated and a least-square fit was applied to the observed $\sigma_{\text {pdd }}$ values, assuming a linear dependence on altitude, $z_{\mathrm{s}}$, latitude, $\phi$, and longitude, $\lambda$ :

$$
\sigma_{\text {pdd }}=D_{\mathrm{a}, \mathrm{j}}+\Gamma_{\mathrm{a}, \mathrm{j}} z_{\mathrm{s}}+C_{\mathrm{a}, \mathrm{j}} \phi+K_{\mathrm{a}, \mathrm{j}} \lambda,
$$

where $\sigma_{\text {pdd }}$ is the standard deviation parameterization. The values of the coefficients found for Equation (4) are given in Table 1. The temperature- and temperature standard deviation parameterizations are based on mean monthly values which constrain Equations (2) and (3) for monthly time integration in Equation (1).

Table 2 presents the modelled and observed values of the mean annual, mean July and mean summer near-surface air temperature standard deviation together with their differences for the 27 AWSs on the GrlS used in this study. The standard deviations show an annual cycle with the smallest values during summer and the largest during winter. Figure 1 shows an example of the annual cycle of the temperature standard deviation from three AWSs located at different elevations. The figure shows that the assumption of a sinusoidal function for the monthly temperature standard deviation is reasonable. Smaller values during summer can be explained by a limiting influence of the surface temperature over a melting snow and ice surface. When the surface temperature reaches the melting point, energy that could potentially raise the near-surface air temperature is used for melting. In the winter no melting occurs and the temperature variations are not limited by the surface temperature. July and August account for the smallest standard-deviation values of the ablation season $\left(<2.0^{\circ} \mathrm{C}\right)$, and the highest values $\left(3.0-6.0^{\circ} \mathrm{C}\right)$ are found in May, June and September. Furthermore, the standard deviation has a clear altitudinal dependence with minor influences by the latitude and longitude as indicated by the coefficients and their rootmean-square difference (RMSD) in Table 1. Both tables show

Table 1. Coefficients for Equation (4) and their root-mean-square difference (RMSD) relative to the observed standard deviation

$$
\begin{array}{ccccc}
D_{\mathrm{a}} & \Gamma_{\mathrm{a}} & \mathrm{C}_{\mathrm{a}} & K_{\mathrm{a}} & \mathrm{RMSD} \\
{ }^{\circ} \mathrm{C} & { }^{\circ} \mathrm{C} \mathrm{km}^{-1} & { }^{\circ} \mathrm{C}^{\circ} \mathrm{N}^{-1} & { }^{\circ} \mathrm{C}^{\circ} \mathrm{W}^{-1} &
\end{array}
$$

Best annual $\left(\sigma_{\mathrm{a}}^{\mathrm{m}}\right)$ fit:

$\begin{array}{lccccc}\text { This study with } K_{\mathrm{a}} & 0.81 & 1.031 & 0.0626 & -0.0159 & 0.56 \\ \text { This study without } K_{\mathrm{a}} & 0.324 & 1.104 & 0.0573 & 0 & 0.57 \\ \text { This study without } K_{\mathrm{a}} & 4.22 & 1.171 & 0 & 0 & 0.63\end{array}$

and $C_{\mathrm{a}}$

$\begin{array}{ccccc}D_{\mathrm{j}} & \Gamma_{\mathrm{j}} & C_{\mathrm{j}} & K_{\mathrm{j}} & \mathrm{RMSD} \\ { }^{\circ} \mathrm{C} & { }^{\circ} \mathrm{C} \mathrm{km}^{-1} & { }^{\circ} \mathrm{C}^{\circ} \mathrm{N}^{-1} & { }^{\circ} \mathrm{C}^{\circ} \mathrm{W}^{-1} & \end{array}$

Best July $\left(\sigma_{\dot{j}}^{\mathrm{m}}\right)$ fit:

$\begin{array}{llllll}\text { This study with } K_{\mathrm{j}} & 2.61 & 1.200 & -0.0136 & -0.0129 & 0.55\end{array}$

$\begin{array}{llllll}\text { This study without } K_{\mathrm{j}} & 2.22 & 1.259 & -0.0178 & 0 & 0.57\end{array}$

$\begin{array}{llllll}\text { This study without } K_{\mathrm{j}} & 1.00 & 1.239 & 0 & 0 & 0.63\end{array}$

and $C_{\mathrm{j}}$ 
Table 2. A comparison between the modelled $\left(\sigma_{\mathrm{a}, \mathrm{j}}^{\mathrm{m}}\right)$ standard deviation distribution and observed data $\left(\sigma_{\mathrm{a}, \mathrm{j}}\right)$ from the stations. $\sigma_{\mathrm{a}}$ and $\sigma_{\mathrm{j}}$ are the mean annual and July standard deviation, respectively. The difference (Diff.) is calculated between the modelled and observed data. Acc. and Abl. denote stations located in the accumulation zone or in the ablation zone. The elevation (Elev.) of the stations is in $\mathrm{ma}$ a.s.l.

\begin{tabular}{|c|c|c|c|c|c|c|c|c|c|}
\hline No. & Station & Location & Elev. & $\sigma_{\mathrm{a}}^{\mathrm{m}}$ & $\sigma_{\mathrm{a}}$ & Diff. & $\sigma_{\mathrm{j}}^{\mathrm{m}}$ & $\sigma_{\mathrm{j}}$ & Diff. \\
\hline 1 & Swiss Camp & Abl. & 1169 & 5.6 & 5.9 & -0.3 & 2.5 & 2.2 & 0.3 \\
\hline 3 & NASA-U & Acc. & 2369 & 7.1 & 7.5 & -0.4 & 3.9 & 4.3 & -0.4 \\
\hline 4 & Humboldt & Acc. & 1995 & 7.0 & 6.8 & 0.2 & 3.5 & 3.7 & -0.2 \\
\hline 5 & Summit & Acc. & 3208 & 8.0 & 8.6 & -0.6 & 5.0 & 4.6 & 0.4 \\
\hline 7 & DYE-2 & Acc. & 2165 & 6.4 & 7.0 & -0.6 & 3.7 & 3.8 & -0.1 \\
\hline 8 & JAR1 & Abl. & 952 & 5.4 & 5.3 & 0.1 & 2.2 & 1.8 & 0.4 \\
\hline 9 & Saddle & Acc. & 2456 & 6.7 & 6.9 & -0.2 & 4.0 & 4.0 & 0.0 \\
\hline 10 & South Dome & Acc. & 2901 & 6.9 & 6.0 & 0.9 & 4.5 & 4.0 & 0.5 \\
\hline 11 & NASA-E & Acc. & 2614 & 7.7 & 7.1 & 0.6 & 4.3 & 3.8 & 0.5 \\
\hline 12 & Craw. Pt.2 & Acc. & 1990 & 6.5 & 6.5 & 0.0 & 3.5 & 4.0 & -0.5 \\
\hline 13 & NGRIP & Acc. & 2950 & 7.9 & 8.9 & -1.0 & 4.7 & 4.9 & -0.2 \\
\hline 14 & NASA-SE & Acc. & 2393 & 6.7 & 6.9 & -0.2 & 4.0 & 4.3 & -0.3 \\
\hline 16 & JAR2 & Abl. & 542 & 5.0 & 4.8 & 0.2 & 1.8 & 1.4 & 0.4 \\
\hline 17 & JAR3 & Abl. & 283 & 5.3 & 4.6 & 0.7 & 2.1 & 1.6 & 0.5 \\
\hline 18 & Peterm. GL & Abl. & 37 & 5.3 & 5.9 & -0.6 & 1.1 & 1.3 & -0.2 \\
\hline 19 & Peterm. ELA & Abl. & 965 & 4.2 & 5.0 & -0.8 & 1.5 & 3.2 & -1.7 \\
\hline 20 & Sermilik1 & Abl. & 350 & 4.6 & 5.8 & -1.2 & 1.5 & 1.4 & 0.1 \\
\hline 21 & Tasilaq2 & Abl. & 300 & 5.0 & 4.1 & 0.9 & 2.2 & 1.6 & 0.6 \\
\hline 22 & Nuuk2 & Abl. & 900 & 5.1 & 4.5 & 0.6 & 2.2 & 1.7 & 0.5 \\
\hline 23 & Imersuaq A & Abl. & 886 & 5.0 & 4.2 & 0.8 & 1.3 & 1.8 & -0.5 \\
\hline 24 & Cryo & Abl. & 200 & 4.8 & 4.8 & 0.0 & 1.7 & 1.7 & 0.0 \\
\hline 25 & s5 & Abl. & 510 & 5.3 & 5.5 & -0.2 & 2.3 & 1.6 & 0.7 \\
\hline 26 & s6 & Abl. & 1020 & 5.8 & 6.0 & -0.2 & 2.9 & 2.4 & 0.5 \\
\hline 27 & s9 & Abl. & 1520 & 6.1 & 5.9 & 0.2 & 2.2 & 2.1 & 0.1 \\
\hline
\end{tabular}

that the smallest standard deviations are found at low elevation $\left(\sigma_{\text {pdd }}<2{ }^{\circ} \mathrm{C}\right)$. The highest standard deviations are found at high surface elevation $\left(\sigma_{\mathrm{pdd}} \sim 7^{\circ} \mathrm{C}\right)$ (Table 2$)$.

To calculate reliable melt rates with the PDD method using a single mean annual value for the whole ice sheet would not be appropriate (Fausto and others, 2009a,b). The new spatially and temporally varying parameterization for $\sigma_{\text {pdd }}$ addresses this problem from an empirical point of view. We suggest that the parameterization presented here should be validated using in situ observational records.

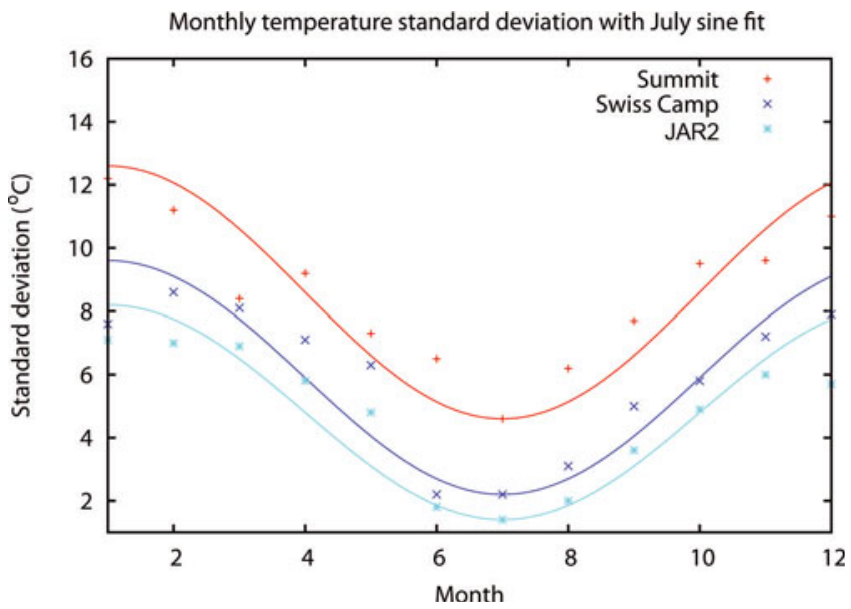

Fig. 1. Monthly temperature standard deviation for three AWSs located in the dry snow zone (Summit), near the equilibrium line (Swiss Camp) and in the ablation zone (JAR2). The lines are from Equation (3) using $\sigma_{\mathrm{a}}^{\mathrm{m}}$ and $\sigma_{\mathrm{j}}^{\mathrm{m}}$ from Table 2.

\section{ACKNOWLEDGEMENTS}

We thank M. van den Broeke for providing temperature data from the K-Transect. Many thanks to two anonymous reviewers for constructive criticism which significantly improved the manuscript. This is a PROMICE (Programme for Monitoring the Greenland Ice Sheet) publication and the paper is published with the permission of the Geological Survey of Denmark and Greenland (GEUS).

Geological Survey of

Denmark and Greenland

Øster Voldgade 10

Robert S. FAUSTO

DK-1350 Copenhagen, Denmark

E-mail: rsf@geus.dk

Cooperative Institute for Research

in Environmental Sciences (CIRES)

Andreas P. AHLSTRØM

Dirk VAN AS

University of Colorado, Boulder,

Colorado 80309-0216, USA

3 September 2011

\section{REFERENCES}

Braithwaite, R.J. 1984. Calculation of degree-days for glacierclimate research. Z. Gletscherkd. Glazialgeol., 20, 1-20.

Fausto, R.S., A.P. Ahlstrøm, D. van As, C.E. Bøggild and S.J. Johnsen. 2009a. A new present-day temperature parameterization for Greenland. J. Glaciol., 55(189), 95-105.

Fausto, R.S., A. Ahlstrøm, D. van As, S.J. Johnsen, P.L. Langen and K. Steffen. 2009b. Improving surface boundary conditions with 
focus on coupling snow densification and meltwater retention in large-scale ice-sheet models of Greenland. J. Glaciol., 55(193), 869-878.

Goelzer, H., P. Huybrechts, M.F. Loutre, H. Goosse, T. Fichefet and A. Mouchet. 2010. Impact of Greenland and Antarctic ice sheet interactions on climate sensitivity. Climate Dyn., 37(5-6), 1005-1018.

Greve, R. 2005. Relation of measured basal temperatures and the spatial distribution of the geothermal heat flux for the Greenland ice sheet. Ann. Glaciol., 42, 424-432.
Greve, R., F. Saito and A. Abe-Ouchi. 2011. Initial results of the SeaRISE numerical experiments with the models SICOPOLIS and ICIES for the Greenland ice sheet. Ann. Glaciol., 52(58), 23-30.

Reeh, N. 1991. Parameterization of melt rate and surface temperature on the Greenland ice sheet. Polarforschung, 59(3), 113-128. Sundal, A.V., A. Shepherd, P. Nienow, E. Hanna, S. Palmer and P. Huybrechts. 2011. Melt-induced speed-up of Greenland ice sheet offset by efficient subglacial drainage. Nature, 469(7331), 521-524. 